\title{
Suicide in a world that is unsure how to value life
}

Previously published at www.cmaj.ca

\section{A Sadly Troubled History: The Meanings of Suicide in the Modern Age John C. Weaver \\ McGill-Queen's University Press; 2009.}

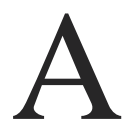
s a psychiatrist, I often speak with troubled people who are considering suicide as a way out of their emotional distress. I find these conversations deeply challenging because our language allows us to talk about self-annihilation in the same 'logical' way we might talk about any other action. I am caught between my professional need to evaluate someone's suicide risk and my human need to understand a distressed person. Prediction relates to statistical facts, to identifying scientifically established risk factors, whereas understanding depends upon society's value systems. In North American society, the possibility that suicide could be considered a rational response to life's problems is controversial. Can suicide be considered rational? If so, how might we decide which motives count as reasonable and which an expression of disturbed thinking, a form of temporary insanity? Can we apply society's definitions of rationality to individual motives for suicide? In a daring methodological move, John Weaver, professor of history at McMaster University, says we must.

It is widely known that a person's risk of suicide increases with age (even taking into consideration recent increases among youths). Men are statistically more likely to kill themselves than women, and people who perceive themselves as a burden to others are most likely to end their own lives. Still, suicide is a relatively rare event. Even the strong association between suicide and depression needs cautious attention, since roughly $93 \%$ of people with chronic,

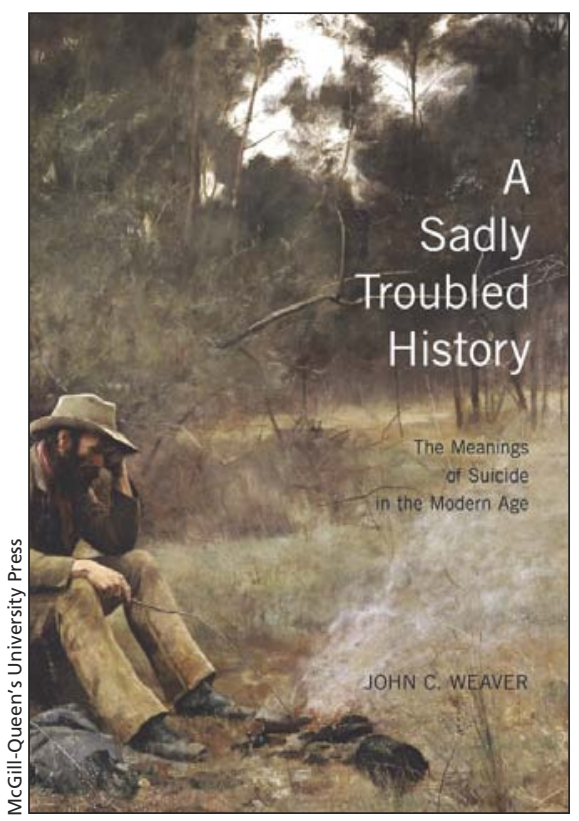

serious depression will not take their own lives.

More associations, gleaned from research on the human genome, link suicide with a tendency to risky and impulsive behaviour. These mathematical relationships have been mined repeatedly from what Ian Hacking describes as an avalanche of numbers originating in large, population databases, allowing us to talk about suicide like any medical problem. Yet an epidemiological approach to suicide has an important limitation. While we might agree that cardiovascular disease is physiologically undesirable, the end result of suicide, death, may be viewed by some sufferers as the best option, as relief from pain, or indeed as a door to an afterlife.

Assuming that an individual act of suicide can be understood in terms of its motives opens some interesting speculations about the role society might play in leading some people to conclude that life is a hopeless situation. For example, we might wonder how, in an age of capitalist consumption, social factors may have contributed to a sense of inadequacy when people, as Weaver writes, “...validate themselves in terms of attainment of property, marketable skills and ideal-type spouses." Historians are interested in how people imagine their past, present and future.

Weaver and his graduate students have, over several years, studied thousands of coroner's reports from New Zealand and Australia to document variations in the motives for suicide over time, during times of war, through economic downturns and between regions with different mental health policies (for example, comparing New Zealand and the Australian state of New South Wales). This approach leads to a different discussion about suicide than one could expect based on aggregated, anonymous data, in which all suicides are addressed together, regardless of differences in their apparent motives. Weaver's goal is primarily social criticism; he would interpret a life story about a chef who commits suicide when his restaurant loses a Michelin star very differently from that of a mother who kills her infant and herself in response to hallucinations.

The book is conceptually divided into two halves. The first is an engaging intellectual history reminiscent of Richard Sennett's work. Historical debates about the social origins of suicide have tended to revolve around the ambitious and creative ideas of the sociologist, Èmile Durkheim (18581917). Aware of the need to deal with the association between madness and suicide, Durkheim "aimed to bypass the morass of insanity and free-will debates ... [by] demolishing psychological explanations." He accomplished this primarily by excluding all deaths attributed to impaired reason from his definition of suicide, justifying himself with the claim that madness was relatively rare in the general population and that suicide related to 
madness was exceedingly rare. But defining away the link between insanity and suicide did not sit well with everyone, particularly 19th-century asylum doctors, who were struggling to define madness and the natural world (rationally) comprehended and as it is comprehended it is rational." Making sense of subtle changes in the motives for suicide across historical periods may be nearly impossible due to periodic recalibrations in the way we

\section{How do we understand cultures that value an honourable death?}

course of mental illness that often appeared inexplicable by social factors alone. Later, the psychoanalyst Karl Menninger (1893-1990), promoted a more general theory of the individual and suicide in his 1938 book Man Against Himself. Here, the focus was on the role of instincts, especially a 'death instinct,' in self-destruction. Menninger believed that psychoanalysis could help strengthen the ego, the part of the Freudian psychic apparatus assigned to negotiate between the irrational and the environment, allowing his patients to live better-adjusted lives. Regardless of its theoretical merits, the reach of psychoanalysis exceeded its grasp and the movement's powerful influence on mental health has faded. By the 1970s, the failures of polarized thinking on suicide invited an interdisciplinary tradition that continues to the present.

In the second half of the book, Weaver leaves the more comfortable place of the theoretical observer to become a vulnerable participant who descends into the emotional and conceptual abyss of rational suicide, in an attempt to get to the bottom of thousands of deaths. As the project describes and categorizes suicides according to their apparent reasons, its methodological limits are exposed. The question of whether suicide can be understood as rational cannot be answered by the idiosyncratic use of statistics to compare shifting individual motives across historical and geographical boundaries. This intense search for reasons behind an act that might itself be unreasonable leads us into a labyrinth with no apparent exit. We are reminded of a logical puzzle attributed to the German philosopher Hegel (1770-1831); "Only as rational is the

talk about mental illness. ${ }^{2}$

Despite its methodological shortfalls, doctors should read this book as a story of humanity that is often avoided and forgotten. Historians have a long tradition of adding meaning to how we understand the world and a growing tradition of providing fresh perspectives on medicine. Is death always to be avoided at any price? How do we understand cultures that value an honourable death, even death by one's own hand, alongside the pursuit of

\section{CREATIVE WORKS}

\section{Reach}

Previously published at www.cmaj.ca

Y esterday, for the third day in a row, the doctor left work early. Yet every night he arrived home late, telling his wife that he needed to walk by the shore a little. His wife treats all this as simply as she can, but each time thinking that next time she will ask him why. Tonight he calls her from his car as he heads out to see another patient on-call. There are weekend plans to arrange, next week will be better, and I love you.

At the house, the man's son opens the door and lets the doctor in. The hall light is on, but otherwise, only a bluish glow from the bedroom. The two talk a little at the door, then the doctor walks to the bedroom alone. A large man lies tilted and still on his bed and a television sends flashes of light across the room, but makes no sound. The room is

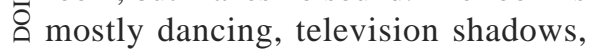

happiness and the good life? These questions are as relevant now as they have ever been, and while our scientific understanding of suicide will undoubtedly grow with future empirical research, the values and debates attached to suicide will also continue to fall outside the purview of quantitative analysis.

Weaver offers us a richer appreciation of the dark side of a society that seems unsure how to value life and equally ambivalent about how to approach death.

\section{Dorian Deshauer MD \\ Associate Editor, Practice CMAJ}

\section{REFERENCES}

1. Burrow JW. The Crisis of Reason: European Thought, 1848-1914. New Haven (CT) and London (UK): Yale University Press; 2000. p. 9.

2. Berrios G. History Of Mental Symptoms: Descriptive Psychopathology Since The Nineteenth Century. Cambridge (UK): Cambridge University Press; 2002. now set against the wall, now part of the night, now off for a moment. The erratic blue light makes the man look unreal. The doctor doesn't turn on the light, he doesn't step into the room, doesn't call to the son, but instead he pauses a moment. Just for a moment, he is still, and he waits.

The doctor recalls stepping into the operating room as a student. His hands and forearms clean and dripping, back first into the room with hands held up in front of him. He turns toward the table, where the anesthetist leans over the patient's arm, a nurse scrubs the patient's belly and two other nurses sort supplies. The resident doctor has put on his gloves and gown, and leans toward the open medical chart. The student doctor turns and stops with his arms up like this, here, dripping a little. No one has noticed him yet. And just for a moment things are still. To keep his hands sterile, he can touch nothing. He 